\title{
Combination of circulating tumor cell enumeration and tumor marker detection in predicting prognosis and treatment effect in metastatic castration-resistant prostate cancer
}

\author{
Kun Chang ${ }^{1,2, *}$, Yun-Yi Kong ${ }^{2,3, *}$, Bo Dai, ${ }^{1,2}$, Ding-Wei Ye ${ }^{1,2}$, Yuan-Yuan Qu ${ }^{1,2}$, Yue \\ Wang $^{1,2}$, Zhong-Wei Jia ${ }^{1,2}$ and Gao-Xiang Li, ${ }^{1,2}$ \\ ${ }^{1}$ Department of Urology, Fudan University Shanghai Cancer Center, Fudan University, Shanghai, China \\ 2 Department of Oncology, Shanghai Medical College, Fudan University, Shanghai, China \\ ${ }^{3}$ Department of Pathology, Fudan University Shanghai Cancer Center, Fudan University, Shanghai, China \\ * Co-first author \\ Correspondence to: Bo Dai, email: bodai1978@126.com
}

Ding-Wei Ye, email: dwyeli@163.com

Keywords: circulating tumor cell, epithelial-mesenchymal transition, metastatic castration-resistant prostate cancer, prognosis, stem cell

Received: August 05, $2015 \quad$ Accepted: October 04, $2015 \quad$ Published: October 19, 2015

This is an open-access article distributed under the terms of the Creative Commons Attribution License, which permits unrestricted use, distribution, and reproduction in any medium, provided the original author and source are credited.

\section{ABSTRACT}

Although circulating tumor cell (CTC) enumeration in peripheral blood has already been validated as a reliable biomarker in predicting prognosis in metastatic castrationresistant prostate cancer (MCRPC), patients with favorable CTC counts (CTC < 5/7.5 $\mathrm{ml}$ ) still experience various survival times. Assays that can reduce patients' risks are urgently needed. In this study, we set up a real-time quantitative polymerase chain reaction (RT-qPCR) method to detect epithelial-mesenchymal transition (EMT) and stem cell gene expression status in peripheral blood to validate whether they could complement CTC enumeration. From January 2013 to June 2014 we collected peripheral blood from 70 mCRPC patients and enumerated CTC in these blood samples using CellSearch system. At the same time, stem cell-related genes (ABCG2, PROM1 and PSCA) and EMT-related genes (TWIST1 and vimentin) were detected in these peripheral blood samples using an RT-qPCR assay. Patient overall survival (OS) and treatment methods were recorded in the follow-up. For patients who received firstline chemotherapy, docetaxel plus prednisone, PSA progression-free survival (PSAPFS) and PSA response rate were recorded. At the time of analysis, 35 patients had died of prostate cancer with a median follow-up of 16.0 months. Unfavorable CTC enumerations (CTC $\geq 5 / 7.5 \mathrm{ml}$ ) were predictive of shorter OS $(p=0.01)$. Also, positive stem cell gene expression indicated poor prognosis in mCRPC patients ( $p$ $=0.01$ ). However, EMT gene expression status failed to show any prognostic value in $0 S(p=0.78)$. A multivariate analysis indicated that serum albumin $(p=0.04)$, ECOG performance status $(p<0.01)$, CTC enumeration $(p=0.02)$ and stem cell gene expression status $(p=0.01)$ were independent prognostic factors for $0 S$. For the 40 patients categorized into the favorable CTC enumeration group, positive stem cell gene expression also suggested poor prognosis $(p<0.01)$. A combined prognostic model consisting of stem cell gene expression and CTC enumeration increased the concordance probability estimated value from 0.716 to 0.889 in comparison with CTC enumeration alone. For patients who received docetaxel plus prednisone as firstline chemotherapy, positive stem cell gene expression suggested a poor PSA-PFS $(p=0.01)$ and a low PSA response rate $(p=0.008)$. However, CTC enumeration and EMT gene expression status did not affect PSA-PFS or PSA response rates. As 


\section{a result, detection of peripheral blood stem cell gene expression could complement CTC enumeration in predicting OS and docetaxel-based treatment effects in mCRPC patients.}

\section{INTRODUCTION}

In the past several years, great progress has been made in the management of metastatic castration-resistant prostate cancer (mCRPC). Several novel therapeutic agents including abiraterone, enzalutamide, cabazitaxel and radium-223 have demonstrated their life-prolonging efficacy in the treatment of mCRPC. However, the development of personalized and sequential management strategies has been hindered by the inability to identify distinct prognostic subgroups. Prostate-specific antigen (PSA), a commonly used prostate-specific biomarker, is not a reliable surrogate for survival end points because of insufficient sensitivity and specificity, and reliable prognostic and predictive biomarkers are urgently needed.

Recently, analysis of circulating tumor cells (CTCs) was shown to be of prognostic and predictive value in mCRPC [1-3]. Most of these studies used the CellSearch (Janssen Diagnostics, Raritan, NJ, USA) system for CTC analysis and found a consistent result, namely that an unfavorable CTC count ( $\geq 5$ cells $/ 7.5 \mathrm{~mL}$ ) before therapy was associated with shorter overall survival (OS) than a favorable CTC count $(<5$ cells $/ 7.5 \mathrm{~mL})$ in $\mathrm{mCRPC}$ patients $[1,2,4]$. Although CellSearch is the only US Food and Drug Administration (FDA)-cleared device for CTC detection and enumeration, it still has some limitations including a comparatively low detection rate and uncertainty of reliable finding in favorable counts. In this regard, although the survival times of patients with high CTC counts are uniformly poor, survival times for those with low CTC counts vary widely $[5,6]$. These limitations may be due to the inability of the CellSearch system to detect CTCs that have undergone epithelialmesenchymal transition (EMT), which results in lost expression of epithelial cell markers and re-expression of stem cell markers.

Therefore, we established a set of sensitive, highly reproducible, and fully standardized real-time quantitative polymerase chain reaction (RT-qPCR) assays to detect stem cell markers (ABCG2, PROM1 and PSCA) and EMT markers (TWIST1 and vimentin) in peripheral blood samples derived from mCRPC patients, and we further evaluated whether these markers could complement CellSearch CTC enumeration in predicting prognosis and treatment effect in mCRPC patients.

\section{RESULTS}

\section{Patient characteristics}

The clinicopathologic characteristics of our 70 mCRPC patients are summarized in Table 1. The median age was 70 years and the median PSA was $24.2 \mathrm{ng} / \mathrm{ml}$ at the time of inclusion. The site of metastasis included: bone (92.9\%), lymph node $(34.3 \%)$, liver (7.1\%), lung $(5.7 \%)$ and other soft tissue (7.1\%). In all, 22 patients developed multi-organ metastasis at the time of the blood draw. After a median follow-up of 18 months (range, 12-26 months), 35 patients died of prostate cancer.

\section{Detection of stem cell gene and EMT gene expression using RT-qPCR}

Relative gene expression (RGE) was calculated using the $2^{-\Delta \Delta \mathrm{Ct}}$ method $(\Delta \Delta \mathrm{Ct}=(\mathrm{Ct}$ gene $-\mathrm{Ct} \beta$-actin $)$ patient sample $-(\mathrm{Ct}$ gene $-\mathrm{Ct} \beta$-actin) healthy volunteer sample) $[7,8]$. Baseline gene expression was precisely quantitated in 20 healthy male control subjects (Table 2). The median RGE for ABCG2, PROM1, TWIST1 and vimentin in mCRPC patients was $0.88,1.38,0.88$ and 0.92 , respectively. The cut-off RGE value was set at $1.78,2.15,1.89$ and 2.75 for ABCG2, PROM1, TWIST1 and vimentin, respectively. As PSCA was not detected in healthy control subjects, PSCA was defined as positive if it could be detected within 40 cycles in RT-qPCR. The detection rate of ABCG2, PROM1, TWIST1, vimentin and PSCA in mCRPC patients is listed in Table 2. In total, $44.29 \%(31 / 70)$ of patients were stem cell gene expression positive as at least one of the three genes (ABCG2, PROM1 and/or PSCA) could be detected, and $47.14 \%$ (33/70) of patients were positive for EMT gene expression as at least one of the two markers (TWIST1 and/or vimentin) could be detected.

\section{Prognostic value of stem cell, EMT gene expression status and CTC enumeration}

Unfavorable CTC enumeration was detected $(\geq 5$ CTCs in $7.5 \mathrm{~mL} \mathrm{~PB})$ in 30 patients $(42.86 \%)$. Univariate analysis found that CTC enumeration and stem cell gene expression status were strong prognostic factors for OS (Table 3, Figures 1 and 2). However, EMT gene expression status had no prognostic value (Table 3, Figure 
Table 1: Baseline clinicopathologic characteristics of $70 \mathrm{mCRPC}$ patients

\begin{tabular}{|l|l|}
\hline Characteristics & Median (Range) \\
\hline Age, years & $70(55-85)$ \\
\hline PSA, ng/ml & $24.2(2.6-269.6)$ \\
\hline Hemoglobin, g/l & $124(69-156)$ \\
\hline ALP, U/1 & $111(47-2779)$ \\
\hline LDH, U/1 & $208(114-2467)$ \\
\hline ALB, g/l & $44.5(32.3-52.2)$ \\
\hline ECOG performance status, No. $(\%)$ & \\
\hline $0-1$ & $63(90.0)$ \\
\hline$\geq 2$ & $7(10.0)$ \\
\hline Gleason score of primary lesion, No. $(\%)$ & \\
\hline $5-7$ & $30(42.9)$ \\
\hline $8-10$ & $40(57.1)$ \\
\hline Site of metastatic disease ${ }^{1}$ No. $(\%)$ & \\
\hline Bone & $65(92.9)$ \\
\hline Lymph node & $24(34.3)$ \\
\hline Liver & $5(7.1)$ \\
\hline Lung & $4(5.7)$ \\
\hline Other soft tissue & $5(7.1)$ \\
\hline
\end{tabular}

PSA, prostate specific antigen; ALP, alkaline phosphatase; LDH, lactate dehydrogenase; ALB, albumin; ECOG, Eastern Cooperative Oncology Group.

${ }^{1} 22$ patients developed multi-organ metastasis.

Table 2: RGE of multiple biomarkers in PBMCs of 70 mCRPC patients and 20 control subjects

\begin{tabular}{|l|l|l|}
\hline & Control subjects & mCRPC patients \\
\hline RGE of ABCG2 & & \\
\hline Median (Minimum-Maximum) & $0.88(0.74-1.43)$ & $0.91(0.06-1289.86)$ \\
\hline Cut-off1 & 1.78 & 1.78 \\
\hline No. of patient > cut-off & 0 & 13 \\
\hline RGE of PROM1 & & \\
\hline Median (Minimum-Maximum) & $1.38(0.54-2.08)$ & $1.32(0.01-222.51)$ \\
\hline Cut-off ${ }^{1}$ & 2.15 & 2.15 \\
\hline No. of patient $>$ cut-off & 0 & 20 \\
\hline RGE of PSCA & & \\
\hline Median (Minimum-Maximum) & $/$ & $/$ \\
\hline Cut-off & \\
\hline No. of patient $>$ cut-off & Undetected & Detected in 5 patients \\
\hline RGE of TWIST1 & 0 & 5 \\
\hline Median (Minimum-Maximum) & & \\
\hline Cut-off & \\
\hline No. of patient $>$ cut-off & $0.88(0.74-1.32)$ & $1.27(0.01-1369.09)$ \\
\hline RGE of Vimentin & 1.89 & 1.89 \\
\hline Median (Minimum-Maximum) & 0 & 27 \\
\hline Cut-off & & \\
\hline No. of patient $>$ cut-off & & $0.85(0.03-40.96)$ \\
\hline & $0.92(0.54-2.08)$ & 2.75 \\
\hline
\end{tabular}

RGE, relative gene expression;

1 The cut-off was set for each gene marker at three standard deviation above the mean expression in healthy control subjects.

${ }^{2}$ As PSCA was not detected in healthy control subjects, PSCA was defined as positive if it can be detected within 40 cycles in the RT-PCR. 
3). The median OS of patients with unfavorable CTC enumeration was significantly shorter than those with favorable CTC enumeration (18 vs. 22 months, $p=0.01$, Figure 1). Moreover, the median OS of patients with stem cell gene expression was significantly shorter than those without stem cell gene expression (16 vs. 22 months, $p=$ 0.01 , Figure 2).

\section{Stem cell gene expression in patients with} favorable CTC enumeration

Of the 40 patients with favorable CTC enumeration (CTCs < 5), $21(52.50 \%)$ had detectable stem cell gene expression. Among them, those with and without stem cell gene expression differed significantly in OS (21 vs. before 26 months, respectively; $\mathrm{p}<0.01$, Figure 4).

\section{Univariate and multivariate analysis of variables affecting $O S$}

In univariate analysis, hemoglobin, ALP, ALB, ECOG performance status, chemotherapy, CTC enumeration and stem cell expression status were significantly associated with shorter OS (Table 3). In multivariate analysis, only ALB, ECOG performance status, CTC enumeration and stem cell gene expression status were independent prognostic factors (Table 3).

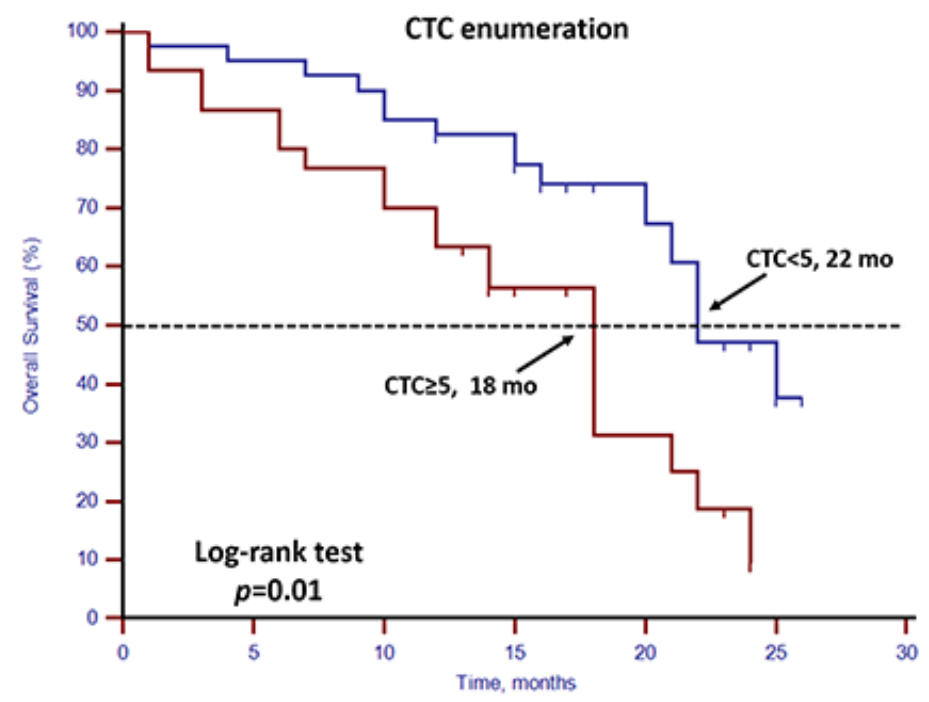

Figure 1: Kaplan-Meier estimates of OS in 70 mCRPC patients according to CTC enumeration. $\log$-rank $p=0.01(\mathrm{Cox}$ HR: 2.44 (95\% CI: 1.23-4.84)).

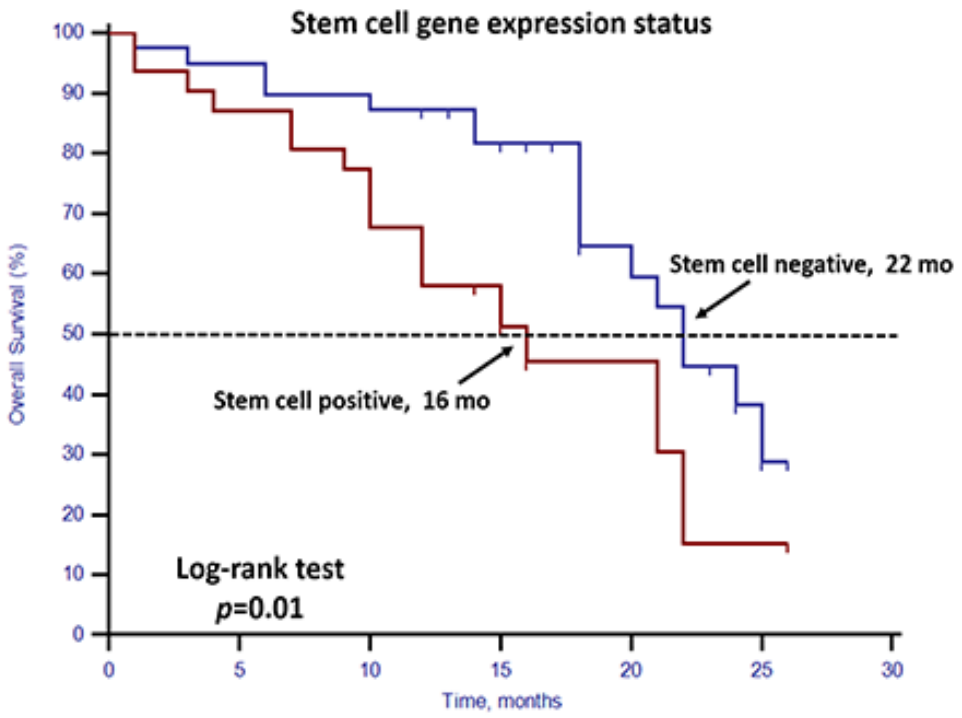

Figure 2: Kaplan-Meier estimates of OS in 70 mCRPC patients according to stem cell gene expression status. Log-rank $p=0.01$ (Cox HR: 2.43 (95\% CI: 1.21-4.87)). 
Table 3: Univariate and multivariate analysis of variables affecting overall survival in 70 mCRPC patients

\begin{tabular}{|l|l|l|l|l|}
\hline Variables & \multicolumn{2}{l|}{ Univariate analysis } & \multicolumn{2}{l|}{ Multivariate analysis } \\
\hline & HR (95\% CI) & $\boldsymbol{P}$ value & HR (95\% CI) & $\boldsymbol{P}$ value \\
\hline Age, years (continuous) & $0.97(0.93 \sim 1.02)$ & 0.25 & - & - \\
\hline PSA, ng/ml (continuous) & $1.00(1.00 \sim 1.00)$ & 0.08 & - & - \\
\hline LDH, U/l (continuous) & $1.00(1.00 \sim 1.00)$ & 0.07 & - & - \\
\hline $\begin{array}{l}\text { Gleason score of primary lesion } \\
(\leq 8 \text { vs }>8)\end{array}$ & $1.09(0.79-1.51)$ & 0.58 & - & - \\
\hline Hemoglobin, g/l (continuous) & $0.97(0.95 \sim 0.99)$ & $<0.01$ & $1.00(0.97 \sim 1.02)$ & 0.69 \\
\hline ALP, U/1 (continuous) & $1.00(1.00 \sim 1.00)$ & $<0.01$ & $1.00(1.00 \sim 1.00)$ & 0.08 \\
\hline ALB, g/l (continuous) & $0.85(0.79 \sim 0.91)$ & $<0.01$ & $0.91(0.83 \sim 0.99)$ & 0.04 \\
\hline $\begin{array}{l}\text { ECOG performance status }(0-1 \text { vs } \\
\geq 2)\end{array}$ & $5.50(2.20-13.76)$ & $<0.01$ & $7.93(2.35 \sim 26.78)$ & $<0.01$ \\
\hline Chemotherapy (No vs Yes) & $0.44(0.22-0.89)$ & 0.02 & $0.54(0.21 \sim 1.39)$ & 0.20 \\
\hline CTC enumeration $(<5$ vs $\geq 5)$ & $2.44(1.23-4.84)$ & 0.01 & $2.73(1.21 \sim 6.13)$ & 0.02 \\
\hline $\begin{array}{l}\text { Stem cell gene expression } \\
\text { (negative vs positive) }\end{array}$ & $2.43(1.21-4.87)$ & 0.01 & $3.18(1.32 \sim 7.65)$ & 0.01 \\
\hline $\begin{array}{l}\text { EMT gene expression (negative vs } \\
\text { positive) }\end{array}$ & $1.10(0.56-2.15)$ & 0.79 & & \\
\hline
\end{tabular}

PSA, prostate specific antigen; ALP, alkaline phosphatase; LDH, lactate dehydrogenase; ALB, albumin; ECOG, Eastern Cooperative Oncology Group; CTC, circulating tumor cell; EMT, epithelial mesenchymal transition.

Table 4: PSA responses rate of 30 patients treated by docetaxel based chemotherapy

\begin{tabular}{|l|l|l|l|}
\hline Variables & Number of patients & PSA response, $\mathbf{n}(\%)$ & $\boldsymbol{P}$ value \\
\hline All patients & 30 & $17(56.7)$ & \\
\hline CTC enumeration & & & \\
\hline$\geq 5$ & 12 & $8(66.7)$ & 0.465 \\
\hline$<5$ & 18 & $9(50.0)$ & \\
\hline Stem cell gene expression & & & \\
\hline Yes & 12 & $3(25.0)$ & 0.008 \\
\hline No & 18 & $14(77.8)$ & \\
\hline EMT gene expression & & & 1.000 \\
\hline Yes & 20 & $11(55.0)$ & \\
\hline No & 10 & $6(60.0)$ & \\
\hline
\end{tabular}

CTC, circulating tumor cell; EMT, epithelial mesenchymal transition.

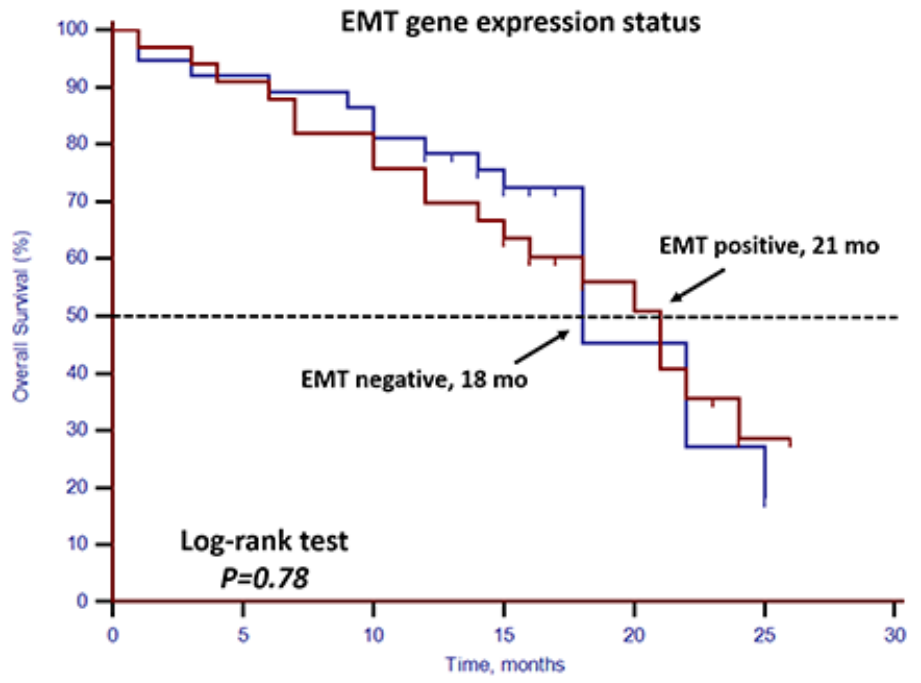

Figure 3: Kaplan-Meier estimates of OS in 70 mCRPC patients according to EMT gene expression status. Log-rank $p=$ 0.78 (Cox HR: 1.10, (95\% CI: 0.56-2.15)). 


\section{Combined prognostic model}

We developed a prognostic model using the combination of stem cell gene expression and CTC enumeration. In this model, the unfavorable group was defined as patients with either positive stem cell gene expression or unfavorable CTC enumeration $(\mathrm{CTC} \geq 5)$, and the favorable group was defined as patients with both negative stem cell gene expression and favorable CTC enumeration. The statistical analysis showed a better concordance probability estimate (CPE) $(0.889)$ in the combined prognostic model than CPE (0.716) in the model using CTC enumeration alone (Figure 5).

\section{Response to docetaxel-based first-line chemotherapy}

For the 30 patients who underwent docetaxelbased first-line chemotherapy, the PSA response rate and PSA progression-free survival (PSA-PFS) were evaluated. Patients with stem cell gene expression had a lower PSA response rate $(25.0 \%, 3 / 12)$ compared with patients without stem cell gene expression $(77.8 \%$, $14 / 18 ; p=0.008$ ) (Table 4). Neither CTC enumeration nor EMT gene expression status showed any predictive value in determining PSA response rates (Table 4). PSAPFS was shorter among patients with stem cell gene expression ( $p=0.01,2.67$ vs. 6.50 months, Figure 6$)$. However, CTC enumeration $(\mathrm{p}=0.52)$ and EMT gene

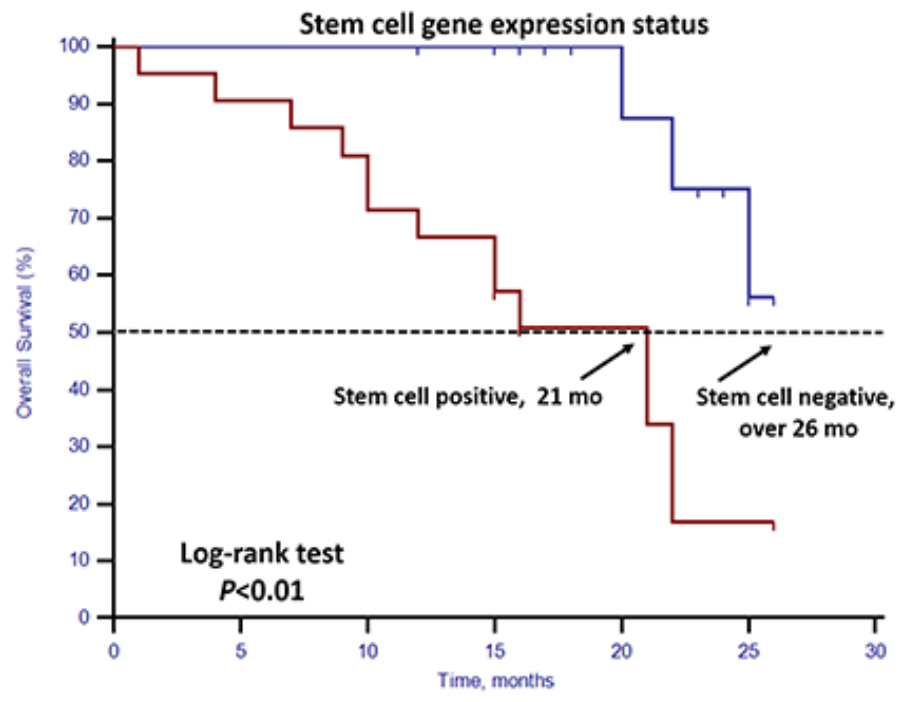

Figure 4: Kaplan-Meier estimates of OS in 40 mCRPC patients in the favorable CTC group according to stem cell gene expression status. Log-rank $p<0.01$ (Cox HR: 6.93, (95\% CI: 1.90-25.31)).

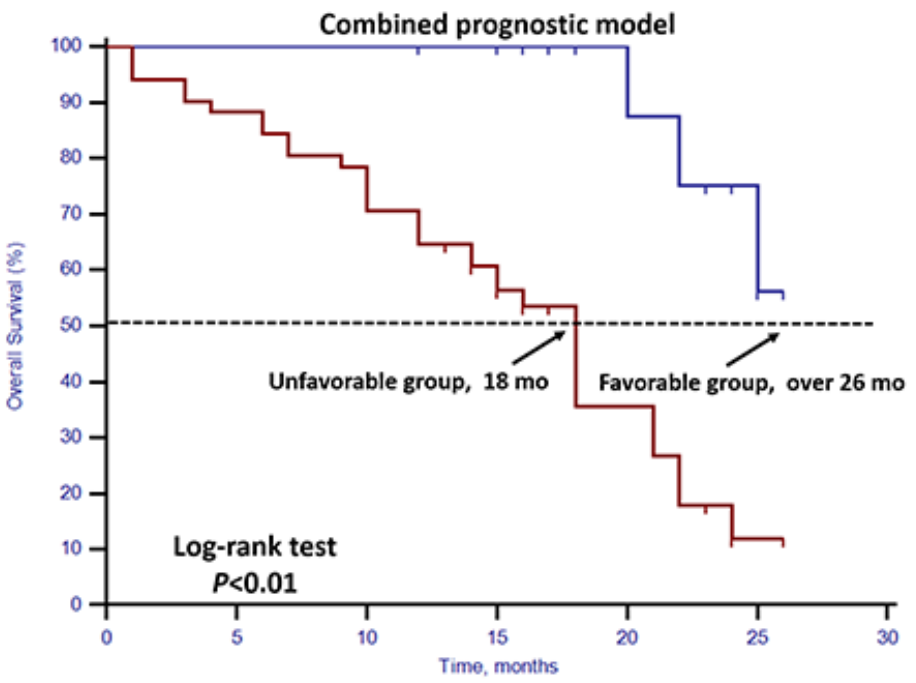

Figure 5: Kaplan-Meier estimates of $\mathrm{OS}$ in $70 \mathrm{mCRPC}$ patients according to combined prognostic model. $\log$-rank $p<$ 0.01 (Cox HR: 7.65, (95\% CI: 2.29-25.57)). 


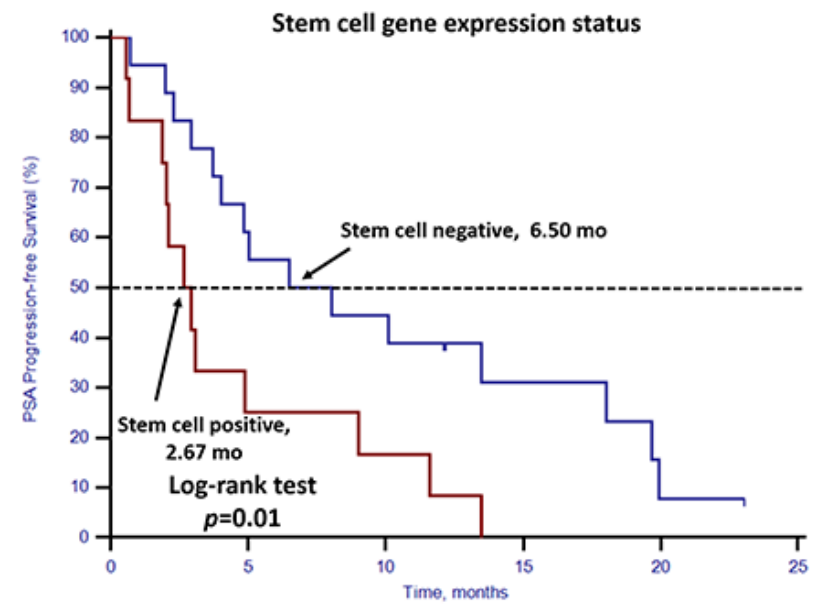

Figure 6: Kaplan-Meier estimates of PSA-PFS in 30 mCRPC patients who received docetaxel-based first-line chemotherapy according to stem cell gene expression status. Log-rank $p=0.01$ (Cox HR: 2.65, (95\% CI: 1.18-5.95)).

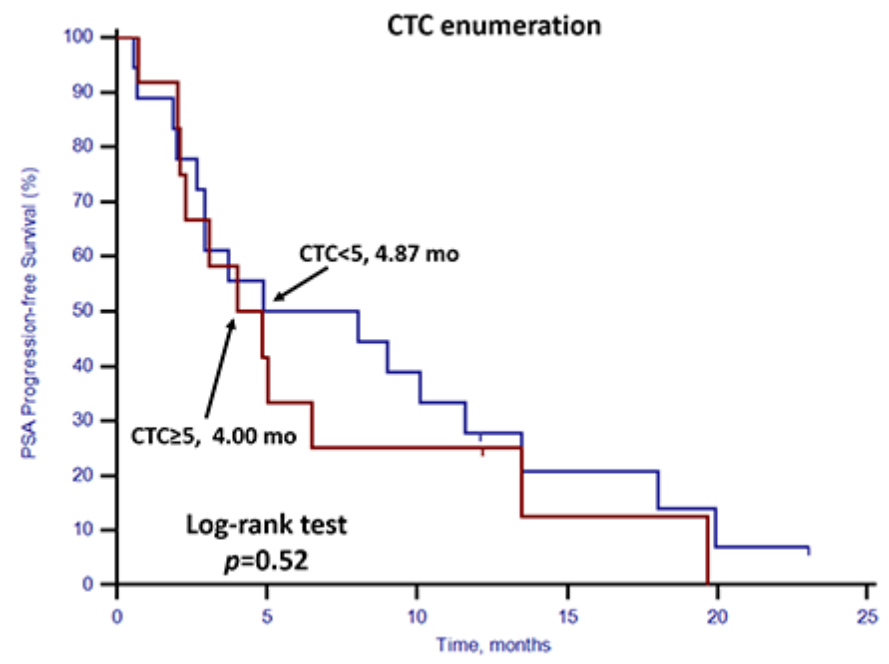

Figure 7: Kaplan-Meier estimates of PSA-PFS in 30 mCRPC patients who received docetaxel-based first-line chemotherapy according to CTC enumeration. Log-rank $p=0.52$ (Cox HR: $1.29,(95 \%$ CI: 0.59-2.82)).

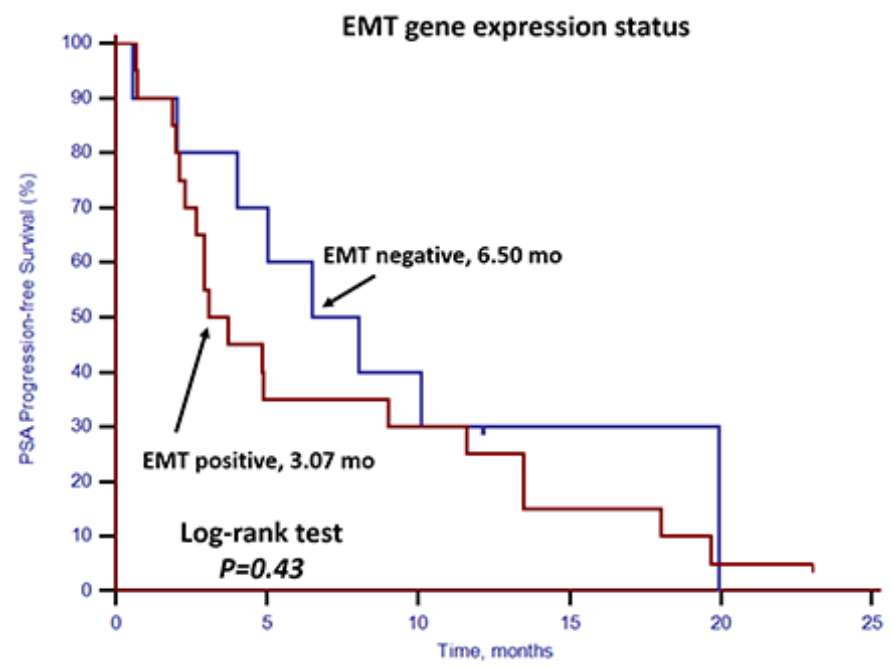

Figure 8: Kaplan-Meier estimates of PSA-PFS in 30 mCRPC patients who received docetaxel-based first-line chemotherapy according to EMT gene expression status. Log-rank $p=0.43$ (Cox HR: 1.40, (95\% CI: 0.61-3.23)). 
expression status $(p=0.43)$ did not show any prognostic value in PSA-PFS (Figures 7 and 8). For the remaining 40 patients who did not receive docetaxel-based first-line chemotherapy, neither stem cell gene expression status nor CTC enumeration nor EMT gene expression status had prognostic value.

\section{DISCUSSION}

In this prospective study, we set up a highly sensitive RT-qPCR-based assay to detect stem cell gene and EMT gene expression in CTCs derived from mCRPC patients. This offers ease of collection and minimal onsite processing. More importantly, we found that both CTC enumeration and stem cell gene expression status were independent prognostic factors for OS in our $\mathrm{MCRPC}$ patients (Table 3, Figures 1 and 2). However, EMT gene expression status had no prognostic value (Figure 3 ). In addition, among the 40 patients with favorable CTC enumeration, those with positive stem cell gene expression experienced significantly shorter OS (Figure 4). Therefore, we established a prognostic model to predict the prognosis of CRPC patients by measuring the CPE using the combination of stem cell gene expression and CTC enumeration, which had a markedly improved risk assessment as shown in the combined prognostic model, which increased the CPE value from 0.716 to 0.889 .

It is not surprising that CTC enumeration served as an independent prognostic factor for OS in our $70 \mathrm{mCRPC}$ patients. The prognostic value of CTC enumeration using the CellSearch system in mCRPC patients has been reported previously. Goldkorn et al. reported that baseline high CTC counts enumerated using the CellSearch before therapy were associated with shorter median survival than low CTC counts in MCRPC patients treated with docetaxel [1]. Scher et al. also found that a biomarker panel containing the CTC number and LDH level was shown to be a surrogate for survival in MCRPC patients treated with abiraterone [2]. Interestingly, we also discovered that not all the patients in the favorable CTC group experienced a good prognosis, especially for the stem cell gene-positive ones. Because enumerating CTCs using the CellSearch system relies on the expression of epithelial markers, we may not be able to detect CTCs if they have undergone intrinsic modifications of their phenotype and lost their epithelial characteristics.

A critical concept that has emerged to explain the result is EMT. It enables epithelial cells to lose their apical-basal polarity, detach from neighboring cells, invade through the surrounding stroma, and become more resistant to apoptosis [9]. During this process, tumor cells lose expression of specific epithelial markers including E-cadherin [10], EpCAM [11], and cytokeratin [12], and gain expression of mesenchymal cytoskeletal and adhesion proteins such as vimentin and N-cadherin [13]. These proteins are thought to be controlled by a family of genes including Snail, Twist, and Zeb [14]. In addition, the process can trigger differentiated cells to acquire a multipotent cancer stem cell-like phenotype. This may mirror developmentally regulated EMT signaling pathways such as Wnt, Notch and Hedgehog, which drive cancer stem cell renewal and maintenance $[15,16]$.

Since most CTC detection methods rely on the capture of cells with antibodies specifically against the epithelial phenotype-specific markers EpCAM and cytokeratins, they may lead to relatively low detection rates. In our study, although the selected EMT markers did not show any prognostic value in predicting OS and response status to chemotherapy, stem cell gene expression status has proved to be a strong prognostic factor for OS. We also found an increased predictive power when combining CTC counts and stem cell gene expression status to discriminate the favorable from the unfavorable group with respect to OS.

In this study, we validated that detection of stem cell gene expression in peripheral blood can be predictive of the response status of docetaxel-based first-line chemotherapy for $30 \mathrm{mCRPC}$ patients. Docetaxel at 75 $\mathrm{mg} / \mathrm{m}^{2}$ once every 3 weeks with prednisone compared with mitoxantrone plus prednisone has been shown to confer a significant survival advantage in patients with mCRPC [17]. In China, docetaxel treatment has been established as standard chemotherapy for mCRPC patients. However, definitive prognostic factors at the initiation of docetaxel chemotherapy associated with disease progression and OS have not been identified.

PSA is not adequate to reflect the status of disease effectively. In $20 \%$ of mCRPC patients who finally respond to chemotherapy proven to prolong OS, an initial PSA increase is seen before the decline. The decline may not occur for up to 12 weeks or even longer [18-20]. Recently, the androgen receptor splice variant 7 (AR-V7) detected in CTCs from mCRPC patients was found to be a reliable marker associated with primary resistance to enzalutamide and abiraterone therapy. However, in followup studies, detection of AR-V7 in CTCs from mCRPC patients was proven to be unassociated with primary resistance to taxane chemotherapy [21].

The mechanisms of cancer stem cells in chemoresistance have long been investigated [22]. ABCG2, a member of ATP-binding cassette (ABC) transporters, is closely related to multi-drug resistance by reducing cytoplasmic chemotherapeutic drug concentrations [23]. Sanchez et al. proved that the pharmacological blockade and knockdown of ABC transporters could partially sensitize prostate cancer cells to chemotherapy [24]. Prominin-1, also known as CD133, has been well documented to be a putative cancer stem cell surface marker in a number of tumors including prostate cancer [25]. Richardson et al. found that in primary prostate cancer tissues, CD133+ cells exhibited characteristics of cancer stem cells including tumorsphere 
formation and the development of prostatic-like acini in SCID mice. [26]. Yang et al. also found that the CD133+ population of the $\mathrm{C} 4-2 \mathrm{~B}$ prostate cancer cell line was closely associated with docetaxel-based chemotherapy [27].

PSCA has been shown to be overexpressed in local as well as metastatic prostate cancer cells [28, 29]. Its expression level increases in cases of higher Gleason score, advanced tumor stage and progression of disease to an androgen-independent state [30, 31]. In our study, the detection of stem cell gene expression in the peripheral blood of $\mathrm{mCRPC}$ patients was associated with chemoresistance. This result suggested that these markers might act as therapeutic targets in the further treatment of prostate cancer.

The relatively small cohort size was one of the limitations of the current study. A validation cohort will be needed in any future study. Another limitation is that only 30 patients actually received docetaxel-based chemotherapy among the 70 patients recruited in this study. Although abiraterone, enzalutamide and cabazitaxel have been approved by the FDA for the treatment of mCRPC, they have not yet been marketed in China. As a result, patients in our cohort did not receive any of these new therapeutic agents during follow-up treatment, which probably contributed to the relatively short OS.

In summary, our study proved that the ABCG2, PROM1 and PSCA-based stem cell gene expression status could be used as a complement to CellSearch to predict OS. Furthermore, detection of these stem cell genes implicated the emergence of primary resistance to docetaxel-based first-line chemotherapy in mCRPC patients. Studies with larger cohorts will be needed to validate our preliminary findings.

\section{MATERIALS AND METHODS}

\section{Prostate cancer cell line}

LNCaP cells were cultured in RPMI1640 medium (GIBCO, Grand Island, NY, USA) containing 10\% fetal bovine serum (FBS, GIBCO) at $37^{\circ} \mathrm{C}$ in a $5 \% \mathrm{CO}_{2}$ atmosphere incubator.

\section{Patient selection and characteristics}

From January 2013 to June 2014, 70 consecutive mCRPC patients (aged 55-85 years) treated at Fudan University Shanghai Cancer Center were included in this prospective study. No patient received any kind of chemotherapy before inclusion. At the time of inclusion, all patients underwent a complete evaluation including: physical examination, Eastern Cooperative Oncology Group (ECOG) performance status, routine clinical laboratory tests, measurement of serum PSA and testosterone levels, thoracic, abdominal and pelvic computed tomography (CT) scans, and a whole-body bone scan. Peripheral blood from each patient was collected after inclusion and before initiation of subsequent therapy. Because the China Food and Drug Administration (CFDA) have not approved abiraterone, enzalutamide and cabazitaxel, 30 of our 70 patients were treated with docetaxel plus prednisone as their first-line therapeutic regimen, and the remaining 40 patients who were intolerant to or refused chemotherapy were treated with ketoconazole, estrogen or traditional Chinese medicine. All patients were closely followed after inclusion. During follow-up, PSA levels were measured once a month in each patient to evaluate the PSA response, best PSA response, and PSA-PFS. According to the PCWG2 criteria, a PSA response referred to a $\geq 50 \%$ decline in PSA levels from baseline and maintained for $\geq 4$ weeks; a best PSA response referred to the maximal percentage decrease in PSA levels from baseline; and PSA progression referred to an increase in PSA levels of $25 \%$ or more above the nadir (and by $\geq 2 \mathrm{ng} / \mathrm{ml}$ ), with confirmation $\geq 4$ weeks later $[32,33]$.

To define baseline expression in peripheral blood of the multiple mRNA markers used in this study, peripheral blood from control subjects was collected. We included 20 healthy male volunteers (aged 35-72 years, with no evidence of malignancy) as control subjects. This study was carried out in accordance with the ethical standards of the Helsinki Declaration II and approved by the Ethics and Scientific Committee of our institution. Written informed consent was obtained from all patients and healthy volunteers before any study-specific investigation was carried out.

\section{Blood sample collection}

To reduce blood contamination by epithelial cells from the skin, the first $2 \mathrm{ml}$ of blood was discarded and the collection tube was disconnected before withdrawing the needle at the end of the procedure. From each patient and healthy volunteer, $17.5 \mathrm{ml}$ of peripheral blood was collected. The first $7.5 \mathrm{ml}$ of blood was stored in a CellSave tube for CTC isolation and enumeration using the CellSearch ${ }^{\mathrm{TM}}$ system (Veridex LLC, Warren, NJ, USA). The remaining $10 \mathrm{ml}$ of blood was stored in an EDTA tube and immediately (within 2 hours) transferred to the laboratory and processed using Ficoll density gradient centrifugation (Ficoll-Paque Plus, TBDscience, China) to isolate peripheral blood mononuclear cells (PBMCs). The separated PBMCs, which contained CTCs, were stored at $-80^{\circ} \mathrm{C}$ until RNA extraction. 


\section{Enumeration of CTCs using the CellSearch ${ }^{\mathrm{TM}}$ system}

Isolation and enumeration of CTCs were performed at the central laboratory of our institution using the FDA-approved CellSearch ${ }^{\mathrm{TM}}$ system. The process has been previously described in detail $[3,34]$. Unfavorable CTC enumeration was defined as $\geq 5$ CTCs in $7.5 \mathrm{ml}$ of peripheral blood $[3,34]$.

\section{RNA isolation and cDNA synthesis}

Total RNA was extracted from the separated PBMCs from $70 \mathrm{mCRPC}$ patients and 20 healthy male volunteers using the TRIzol Reagent (Invitrogen, USA). RNA samples extracted from $\mathrm{LNCaP}$ cells served as a positive control. All RNA preparation and handling procedures were performed under RNase-free conditions in a laminar flow hood. Optical density measurements at 260 and 280 $\mathrm{nm}$ were used to quantify and assess the purity of the RNA. Reverse transcription of RNA was carried out with the PrimeScript RT Master Mix system (TaKaRa, Dalian, China). Complementary DNA was synthesized from $2 \mu \mathrm{g}$ of total RNA isolated from PBMCs in a total volume of 20 $\mu 1$, according to the manufacturer's instructions.

\section{Cancer stem cell gene and EMT gene expression analysis using RT-qPCR}

RT-qPCR was performed using the 7900HT Fast RT-PCR System (Applied Biosystems, USA). The $\beta$-actin gene was used to normalize gene expression levels. Probes including ABCG2 (catalog no. Hs01053790_m1), PROM1 (catalog no. Hs01009250_m1), PSCA (catalog no. Hs04177224_g1), TWIST1 (catalog no. Hs01675818 s1), vimentin (catalog no. Hs00185584_m1) and $\beta$-actin (catalog no. Hs01060665_m1) were purchased from ABI Applied Biosystems. Relative gene expression (RGE) was calculated using the $2^{-\Delta \Delta \mathrm{Ct}}$ method $(\Delta \Delta \mathrm{Ct}=(\mathrm{Ct}$ gene - Ct $\beta$-actin) patient sample - (Ct gene $-\mathrm{Ct} \beta$-actin $)$ healthy volunteer sample) [7, 8]. RT-qPCR positivity was defined as gene expression greater than the cut-off threshold, which was set for each gene marker at three standard deviations above the mean expression in healthy control blood samples [8]. Stem cell gene expression was classified as positive if expression of one of the three stem cell genes (ABCG2, PROM1, and PSCA) was detected and EMT gene expression was classified as positive if expression of one of the two EMT genes (TWIST1 and vimentin) was detected.

\section{Statistical analysis}

OS and PSA-PFS were calculated using the Kaplan-Meier method with the log-rank test to assess differences between groups. Univariate and multivariate analyses of prognostic factors were conducted using the Cox proportional hazards model. Because of the limited number of patients, only the variables that appeared to have a significant impact on OS by univariate analysis were included in the multivariate analysis. To evaluate the PSA response rate according to CTC enumeration, stem cell and EMT gene expression status, Fisher's exact test was used.

Prognostic significance of CTC enumeration and the combined prognostic model were assessed using the concordance probability estimate $(\mathrm{CPE})$. The $\mathrm{CPE}$ measures the level of concordance between the survival time and the prognostic index, based on the linear combination of covariates in the Cox model, to provide an unbiased assessment of discrimination with survival data $[6,34]$. CPE values range from $0.5-1.0$, with 1.0 representing perfect concordance between the prognostic index and survival time $[6,34]$. All statistical tests were done using SPSS, version 20 (SPSS Inc., Chicago, IL, USA) and R statistics package, version 2.8.1 (http:// www.r-project.org/). A $P$-value $<0.05$ was considered to indicate statistical significance.

\section{ACKNOWLEDGMENTS}

This study was supported by a grant from the Guide Project of Science and Technology Commission of Shanghai Municipality (124119a7300), and a grant from the Outstanding Young Talent Training Plan of Shanghai Municipal Commission of Health and Family Planning (XYQ2013102).

\section{CONFLICTS OF INTEREST}

All authors declare no competing financial interests.

\section{Author contributions}

$\mathrm{KC}$, YYK and BD designed the study, analyzed and interpreted the clinical data, and wrote and revised the manuscript. BD and DWY supervised the project. $\mathrm{KC}$ and ZWJ conducted the whole experiment. YYQ, YW and GXL helped us follow up with the patients. All authors approved the final version and agreed to publish the manuscript.

\section{REFERENCES}

1. Goldkorn A, Ely B, Quinn DI, Tangen CM, Fink LM, Xu T, 
Twardowski P, Van Veldhuizen PJ, Agarwal N, Carducci MA, Monk JR, Datar RH, Garzotto M, et al. Circulating tumor cell counts are prognostic of overall survival in SWOG S0421: a phase III trial of docetaxel with or without atrasentan for metastatic castration-resistant prostate cancer. J Clin Oncol. 2014;32: 1136-1142.

2. Scher HI, Heller G, Molina A, Attard G, Danila DC, Jia X, Peng W, Sandhu SK, Olmos D, Riisnaes R, McCormack $\mathrm{R}$, Burzykowski $\mathrm{T}$, Kheoh $\mathrm{T}$, et al. Circulating tumor cell biomarker panel as an individual-level surrogate for survival in metastatic castration-resistant prostate cancer. J Clin Oncol. 2015;33: 1348-1355.

3. de Bono JS, Scher HI, Montgomery RB, Parker C, Miller MC, Tissing H, Doyle GV, Terstappen LW, Pienta KJ, Raghavan D. Circulating tumor cells predict survival benefit from treatment in metastatic castration-resistant prostate cancer. Clin Cancer Res. 2008; 14: 6302-6309.

4. Danila DC, Fleisher M, Scher HI. Circulating tumor cells as biomarkers in prostate cancer. Clin Cancer Res. 2011;17:3903-3912.

5. Scher HI, Jia X, de Bono JS, Fleisher M, Pienta KJ, Raghavan D, Heller G. Circulating tumour cells as prognostic markers in progressive, castration-resistant prostate cancer: a reanalysis of IMMC38 trial data. Lancet Oncol. 2009;10:233-239.

6. Danila DC, Anand A, Schultz N, Heller G, Wan M, Sung CC, Dai C, Khanin R, Fleisher M, Lilja H, Scher HI. Analytic and clinical validation of a prostate cancerenhanced messenger RNA detection assay in whole blood as a prognostic biomarker for survival. Eur Urol. 2014;65:1191-1197.

7. Livak KJ, Schmittgen TD. Analysis of relative gene expression data using real-time quantitative PCR and the 2(-Delta Delta C(T)) Method. Methods. 2001;25:402-408.

8. Chong MH, Zhao Y, Wang J, Zha XM, Liu XA, Ling LJ, $\mathrm{Du} \mathrm{Q}$, Wang S. The dynamic change of circulating tumour cells in patients with operable breast cancer before and after chemotherapy based on a multimarker QPCR platform. Br J Cancer. 2012;106:1605-1610.

9. Vincent-Salomon A, Thiery JP. Host microenvironment in breast cancer development: epithelial-mesenchymal transition in breast cancer development [J]. Breast Cancer Res. 2003;5:101-106.

10. Comijn J, Berx G, Vermassen P, Verschueren K, van Grunsven L, Bruyneel E, Mareel M, Huylebroeck D, van Roy F. The two-handed E box binding zinc finger protein SIP1 downregulates E-cadherin and induces invasion. Mol Cell. 2001;7:1267-1278.

11. Went PT, Lugli A, Meier S, Bundi M, Mirlacher M, Sauter G, Dirnhofer S. Frequent EpCam protein expression in human carcinomas. Hum Pathol. 2004;35:122-128.

12. Savagner P. The epithelial-mesenchymal transition (EMT) phenomenon. Ann Oncol. 2010;21 Suppl 7:i89-i92.

13. Kokkinos MI, Wafai R, Wong MK, Newgreen DF,
Thompson EW, Waltham M. Vimentin and epithelialmesenchymal transition in human breast cancer-observations in vitro and in vivo. Cells Tissues Organs 2007;185:191-203.

14. Berx G, Raspe E, Christofori G, Thiery JP, Sleeman JP. Pre-EMTing metastasis? Recapitulation of morphogenetic processes in cancer. Clin Exp Metastasis. 2007;24:587-597.

15. Malanchi I, Peinado H, Kassen D, Hussenet T, Metzger D, Chambon P, Huber M, Hohl D, Cano A, Birchmeier W, Huelsken J. Cutaneous cancer stem cell maintenance is dependent on beta-catenin signalling. Nature. 2008;452:650-653.

16. Peacock CD, Watkins DN. Cancer stem cells and the ontogeny of lung cancer. J Clin Oncol 2008;26:2883-2889.

17. Tannock IF, de Wit R, Berry WR, Horti J, Pluzanska A, Chi KN, Oudard S, Theodore C, James ND, Turesson I, Rosenthal MA, Eisenberger MA. Docetaxel plus prednisone or mitoxantrone plus prednisone for advanced prostate cancer. N Engl J Med. 2004;351:1502-1512.

18. Berthold DR, Pond GR, Roessner M, de Wit R, Eisenberger $\mathrm{M}$, Tannock AI. Treatment of hormone-refractory prostate cancer with docetaxel or mitoxantrone: relationships between prostate-specific antigen, pain, and quality of life response and survival in the TAX-327 study. Clin Cancer Res. 2008;14:2763-2767.

19. Madan RA, Pal SK, Sartor O, Dahut WL. Overcoming chemotherapy resistance in prostate cancer. Clin Cancer Res. 2011;17:3892-3902.

20. Fleming MT, Morris MJ, Heller G, Scher HI. Post-therapy changes in PSA as an outcome measure in prostate cancer clinical trials. Nat Clin Pract Oncol. 2006;3:658-667.

21. Antonarakis ES, Lu C, Luber B, Wang H, Chen Y, Nakazawa M, Nadal R, Paller CJ, Denmeade SR, Carducci MA, Eisenberger MA, Luo J. Androgen Receptor Splice Variant 7 and Efficacy of Taxane Chemotherapy in Patients With Metastatic Castration-Resistant Prostate Cancer. JAMA. Oncol 2015; 1:582-591.

22. McCubrey JA, Abrams SL, Stadelman K, Chappell WH, Lahair M, Ferland RA, Steelman LS. Targeting signal transduction pathways to eliminate chemotherapeutic drug resistance and cancer stem cells. Adv Enzyme Regul 2010;50:285-307.

23. Schnepf R, Zolk O. Effect of the ATP-binding cassette transporter ABCG2 on pharmacokinetics: experimental findings and clinical implications. Expert Opin Drug Metab Toxicol. 2013;9:287-306.

24. Sanchez C, Mercado A, Contreras HR, Mendoza P, Cabezas J, Acevedo C, Huidobro C, Castellon EA. Chemotherapy sensitivity recovery of prostate cancer cells by functional inhibition and knock down of multidrug resistance proteins. Prostate. 2011;71:1810-1817.

25. Pellacani D, Oldridge EE, Collins AT, Maitland NJ. Prominin-1 (CD133) Expression in the Prostate and Prostate Cancer: A Marker for Quiescent Stem Cells. Adv Exp Med 
Biol. 2013;777:167-184.

26. Richardson GD, Robson CN, Lang SH, Neal DE, Maitland NJ, Collins AT. CD133, a novel marker for human prostatic epithelial stem cells. J Cell Sci. 2004;117:3539-3545.

27. Yang DR, Ding XF, Luo J, Shan YX, Wang R, Lin SJ, Li G, Huang CK, Zhu J, Chen Y, Lee SO, Chang C. Increased chemosensitivity via targeting testicular nuclear receptor 4 (TR4)-Oct4-interleukin 1 receptor antagonist (IL1Ra) axis in prostate cancer CD133+ stem/progenitor cells to battle prostate cancer. J Biol Chem. 2013;288:16476-16483.

28. Raff AB, Gray A, Kast WM. Prostate stem cell antigen: a prospective therapeutic and diagnostic target. Cancer Lett. 2009;277:126-132.

29. Reiter RE, Gu Z, Watabe T, Thomas G, Szigeti K, Davis E, Wahl M, Nisitani S, Yamashiro J, Le Beau MM, Loda M, Witte ON. Prostate stem cell antigen: a cell surface marker overexpressed in prostate cancer. Proc Natl Acad Sci. U S A 1998;95:1735-1740.

30. Taeb J, Asgari M, Abolhasani M, Farajollahi MM, Madjd Z. Expression of prostate stem cell antigen (PSCA) in prostate cancer: a tissue microarray study of Iranian patients. Pathol Res Pract. 2014;210:18-23.

31. Gu Z, Thomas G, Yamashiro J, Shintaku IP, Dorey F, Raitano A, Witte ON, Said JW, Loda M, Reiter RE. Prostate stem cell antigen (PSCA) expression increases with high gleason score, advanced stage and bone metastasis in prostate cancer. Oncogene. 2000;19:1288-1296.

32. Scher HI, Halabi S, Tannock I, Morris M, Sternberg CN, Carducci MA, Eisenberger MA, Higano C, Bubley GJ, Dreicer R, Petrylak D, Kantoff P, Basch E, et al. Design and end points of clinical trials for patients with progressive prostate cancer and castrate levels of testosterone: recommendations of the Prostate Cancer Clinical Trials Working Group. J Clin Oncol. 2008;26:1148-1159.

33. Antonarakis ES, Lu C, Wang H, Luber B, Nakazawa M, Roeser JC, Chen Y, Mohammad TA, Chen Y, Fedor HL, Lotan TL, Zheng Q, De Marzo AM, et al. AR-V7 and resistance to enzalutamide and abiraterone in prostate cancer. N Engl J Med. 2014;371:1028-1038.

34. Danila DC, Heller G, Gignac GA, Gonzalez-Espinoza R, Anand A, Tanaka E, Lilja H, Schwartz L, Larson S, Fleisher M, Scher HI. Circulating tumor cell number and prognosis in progressive castration-resistant prostate cancer. Clin Cancer Res. 2007;13:7053-7058. 